\title{
Interhemispheric gene expression differences in the cerebral cortex of humans and macaque monkeys
}

\author{
Gerard Muntané $^{1,2}$, Gabriel Santpere ${ }^{2}$, Andrey Verendeev ${ }^{1}$, William W. Seeley ${ }^{3}$, Bob \\ Jacobs $^{4}$, William D. Hopkins ${ }^{5}$, Arcadi Navarro ${ }^{2}$, and Chet C. Sherwood ${ }^{1}$ \\ ${ }^{1}$ Department of Anthropology and Center for the Advanced Study of Human Paleobiology, The \\ George Washington University, Washington, DC 20052, USA \\ ${ }^{2}$ Institut Biologia Evolutiva, Universitat Pompeu Fabra - CSIC, Barcelona 08003, Spain \\ ${ }^{3}$ Memory and Aging Center, Department of Neurology, University of California, San Francisco, CA \\ 94158, USA \\ ${ }^{4}$ Laboratory of Quantitative Neuromorphology, Neuroscience Program, Colorado College, \\ Colorado Springs, Colorado 80903, USA
}

${ }^{5}$ Neuroscience Institute and the Language Research Center, Georgia State University, Atlanta, GA 30302, USA

\section{Abstract \\ Handedness and language are two well-studied examples of asymmetrical brain function in humans. Approximately $90 \%$ of humans exhibit a right-hand preference and the vast majority show left-hemisphere dominance for language function. Although genetic models of human handedness and language have been proposed, the actual gene expression differences between cerebral hemispheres in humans remain to be fully defined. In the present study, gene expression profiles were examined in both hemispheres of three cortical regions involved in handedness and language in humans and their homologues in rhesus macaques: ventrolateral prefrontal cortex (VFC), posterior superior temporal cortex (STC), and primary motor cortex (M1C). Although the overall pattern of gene expression was very similar between hemispheres in both humans and macaques, weighted gene correlation network analysis (WGCNA) revealed gene co-expression modules associated with hemisphere, which are different among the three cortical regions examined. Notably, a receptor-enriched gene module in STC was particularly associated to hemisphere and showed different expression levels between hemispheres only in humans.}

\section{Keywords}

brain asymmetry; brain evolution; language; WGCNA; cerebral cortex; gene networks

\footnotetext{
"To whom correspondence should be addressed: Gerard Muntané, Institut de Biologia Evolutiva, Universitat Pompeu Fabra - CSIC, Doctor Aiguader 88, Office 350.05, PRBB Building. 08003 Barcelona Barcelona, Spain. gerard.muntane @ upf.edu and/or gmunta@yahoo.es; Ph: +34 933160804.

Conflict of interest: The authors declare no competing financial interests.

Accession code. Macaque microarrays were submitted to National Center for Biotechnology Information (NCBI) Gene Expression Omnibus (GEO accession number GSE76644).
} 


\section{Introduction}

Humans display structural and functional asymmetries in brain organization, most notably in relation to handedness and language. For example, right-handedness across all human societies exceeds $85 \%$ (Cashmore et al., 2008). No comparable species-level handedness bias has been observed in rhesus macaques (Macaca mulatta; Fitch and Braccini, 2013; Papademetriou et al., 2005) or other monkeys (Vauclair and Meguerditchian, 2007; Spinozzi, 2007), although chimpanzees display some degree of population-level hand preference for certain manual activities (Hopkins et al., 2005, 2004; Hopkins and Leavens, 1998). Archaeological data support the notion that increased right-handedness evolved along the human lineage (Uomini, 2009, Frayer et al., 2012, Frayer et al., 2010; Lozano et al., 2009).

The left hemisphere specialization for language is one of the earliest observations of human brain asymmetry, dating back to the $19^{\text {th }}$ century (Broca, 1865; Wernicke, 1874). In particular, two cerebral cortical regions have attracted the most attention for their involvement in speech production, grammatical processes, and language comprehension: Broca's area of the ventrolateral prefrontal cortex (VFC) and Wernicke's area of the posterior superior temporal cortex (STC) (Dapretto and Bookheimer, 1999; Dronkers and Ogar, 2004). Both cortical areas show population-level left hemisphere functional dominance in humans (Hugdahl and Westerhausen, 2012). Which aspects of vocal communication are asymmetrically controlled in nonhuman primate brains or how homologues of these structures are involved in vocal processing is not yet entirely clear (Gilda-Costa et al. 2006; Sun and Walsh, 2006; Wilson et al. 2015). Nonetheless, chimpanzees also show left-sided enlargement in some aspects of the morphology of the homologues of both cortical areas (Cantalupo and Hopkins, 2001; Gannon et al., 1998; Spocter et al., 2010).

Handedness and language are strongly associated, with about $97 \%$ of right-handed individuals demonstrating left hemisphere specialization for language function (Geschwind et al., 2002). Although it is possible that language and handedness originated independently in human evolution, it has been argued that these specializations evolved in tandem with each other (Corballis, 2003). Both cerebral language dominance and handedness are heritable traits, with additive genetic effects estimated to account for about $50 \%$ and $25 \%$ of the variance, respectively (Geschwind et al., 2002). However, for decades, investigators have focused on the neuroanatomical and behavioral differences between humans and other species, with relatively scant effort devoted to exploring genetic and environmental factors that determine individual brain lateralization.

Although heritability estimates would be consistent with single gene causation models (Geschwind et al., 2002), multi-locus models of combined weak effects have been shown to be more suitable to explain the genetic background of these complex brain and behavioral phenotypes (Armour et al., 2014; McManus et al., 2013, Somers et al. 2015). At the gene expression level, several studies have focused on elucidating lateralized brain functions in humans; however, the existence of single genes with differential inter-hemispheric expression is still under debate. It has been suggested that the number of such genes is small, if any (Johnson et al., 2009; Pletikos et al., 2013), although lateralization is more robust when assessed at the level of gene functional groups (Karlebach and Francks, 2015). 
Nonetheless, studies of fetal human brains have identified genes with lateralized expression

(Sun et al., 2005). Of these, LMO4 is the most notable, especially since unilateral manipulation of its expression in mouse cortex results in a high degree of functional behavioral laterality ( $\mathrm{Li}$ et al. 2013). To our knowledge, few genome-wide association studies (GWAS) in humans have examined handedness (McManus et al., 2013) and none has been conducted for language lateralization (Ocklenburg et al., 2014). Nevertheless, human neuroimaging literature suggests that functional leftward lateralization is evident in infancy and becomes more robust and pronounced in adulthood, suggesting a strong genetic component to this trait (Agcaoglu et al., 2015; Groen et al., 2012). In the current study, we performed microarray analyses of human and rhesus macaque monkey brains to explore gene expression between hemispheres in specific neocortical regions involved in lateralized functions, including the VFC, STC and primary motor cortex (M1C). Moreover, weighted gene co-expression network analysis (WGCNA; Zhang and Horvath, 2005) was also performed to identify region- and hemisphere-associated gene co-expression modules.

Investigations to date have been unable to clearly identify genetic variants correlated with brain asymmetry in humans in cortical regions involved in language and handedness. Therefore, in this study we tested whether more subtle variation in expression level among genes interacting in networks might show hemispheric asymmetry in humans. To test whether such hemispheric asymmetry in co-expression networks of humans are evolutionarily novel, we also analyzed homologous cortical regions in macaque brains.

\section{Materials and Methods}

\section{Human and rhesus macaque samples}

In the present study, we used a subset of microarray data from a publicly available dataset (Kang et al., 2011), including data from three human neocortical areas: ventrolateral prefrontal cortex (VFC), superior temporal cortex (STC) and primary motor cortex (M1C). CEL files were retrieved from the GEO database (GSE25219). 74 brain samples from 17 different individuals were included in the analyses, ranging from adolescence to late adulthood (periods $12-15$ in Kang et al. 2015) and with a RIN number $\geq 8$. Among the samples used, both sexes were represented (mean age was $36.4 \pm 18.7$ ), including 38 female and 36 male samples (Supplementary Table 1).

Rhesus macaque (Macaca mulatta) whole brains were obtained from Wisconsin National Primate Research Center (Madison, WI) and University of California at Davis. All animals were housed in accordance with NIH, USDA, and AWA regulations, and overseen by the IACUCs of the respective institutions (National Research Council (US) Committee for the Update of the Guide for the Care and Use of Laboratory Animals, 2011). Frozen brain samples were stored at $-80^{\circ} \mathrm{C}$ until use (Table 1). In total, 30 samples including STC, VFC and $\mathrm{M} 1 \mathrm{C}$ homologous areas from macaques were obtained from brains dissected from 5 adult individuals ( 3 females and 2 males with mean age $5.5 \pm 2.4$, Table 1). From each hemisphere, samples were dissected from the inferior ramus of the arcuate sulcus in the ventrolateral prefrontal cortex (homologous to area 44 of human VFC; Petrides et al. 2012), the posterior superior temporal cortex (homologous to human STC; Gannon et al., 2008), and the precentral gyrus from the region corresponding to forelimb representation in the 
primary motor cortex (M1C). Cortical areas dissected in macaque brains are displayed in Figure 1A. RNA extraction and hybridization were performed following standard protocols.

\section{Array hybridizations for macaque samples}

For each specimen, 50-100 mg of tissue was homogenized in $1 \mathrm{~mL}$ of TRI reagent (Applied Biosytems/Ambion, Austin, TX) in a glass-Teflon tubes and RNA extraction was performed following the manufacturer's protocols. Total RNA was assessed for quality with an Agilent 2100 Bioanalyzer G2939A (Agilent Technologies, Santa Clara, CA) and Nanodrop 8000 spectrophotometer (Thermo Scientific/Nanodrop, Wilmington, DE). Only the DNA-free RNA isolations with ABS 260/280 ratios above 1.9 and with RIN number over 8 were selected for further analyses.

Hybridization targets were prepared with an Ambion WT Expression Kit (Applied Biosystems/Ambion, Austin, TX) and Affymetrix GeneChip WT Terminal Labeling Kit from total RNA, hybridized to individual GeneChip ${ }^{\circledR}$ Human Gene 2.0 ST arrays in Affymetrix GeneChip ${ }^{\circledR}$ hybridization oven 645. Microarrays were washed in Affymetrix GeneChip ${ }^{\circledR}$ Fluidics Station 450 and scanned with Affymetrix GeneChip® Scanner 7G according to standard Affymetrix GeneChip ${ }^{\circledR}$ hybridization, wash, and stain protocols (Affymetrix, Santa Clara, CA).

\section{Gene Expression Analysis}

Human and macaque datasets were always analyzed independently to avoid potential problems with cross-platform normalization (Rudy and Valafar, 2011). In the human dataset 22,011 probes were collapsed to 17,634 annotated genes. In rhesus macaque samples the Affymetrix Macaque Gene 2.0 ST Array platform was used, which included 40,489 probes, of which 25,664 were collapsed to annotated genes (63\%). Of these, 11,554 (45\%) where shared by both platforms and analyzed independently in both datasets.

Microarray data were analyzed in R using packages implemented in Bioconductor (Gentleman et al., 2004). Expression values were normalized using the RMA (Robust Multichip Average) algorithm (Irizarry et al., 2003) and differential expression analysis was performed using the Limma package (Gentleman et al., 2005). The linear modeling and empirical Bayesian moderated t-test (Smyth, 2004) implemented with the Limma function eBayes was applied to pairwise comparisons to identify differential expression between hemispheres in each brain region analyzed in human and macaque data. Gene enrichment was assessed using GOrilla (Eden et al., 2009), and then visualized using REViGO (Supek et al., 2011). The statistical significance threshold level for multiple testing was adjusted using BH FDR analysis $(\mathrm{P}<0.05)$.

\section{Principal component analyses (PCA) and distance correlations}

Principal component analyses (PCA) were performed using the prcomp function in $\mathrm{R}$ software (R core team, 2014) for humans and macaques independently. In addition, vectorial Euclidian distances were calculated from right to left hemispheres within each individual sample based on the Spearman Rank correlation $((1-r) / 2)$. 


\section{Weighted Gene Co-expression Network Analysis}

WGCNA has the power to reveal the underlying organization of the transcriptome of a system based on the degree of gene neighborhood sharing defined as co-expression relationships (Konopka et al., 2012; Miller et al., 2010; Oldham et al., 2006; Winden et al., 2009). It also alleviates the multiple comparison problem inherent in the data: allowing for only a few modules to be tested for associations instead of thousands of genes (de la Fuente, 2010; Langfelder and Horvath, 2008; Zhang and Horvath, 2005). Co-expression network analyses were performed in $\mathrm{R}$ software and the WGCNA library following standard protocols (Langfelder et al., 2011, 2008). For computational efficiency, weighted networks were generated using the subset of genes showing consistent levels of expression across samples from the human dataset and the macaque dataset. Expression probes had to reach the threshold of a mean $\log 2$ expression value of 6 across all samples to be included in the WGCNA analyses (met by 8,825 of the 11,554 (76\%) overlapping genes). Co-expression network analyses were performed in R software and the WGCNA library following standard protocols (Langfelder et al., 2011, 2008) and were constructed for the human samples by grouping: 1) cortical areas (STC, VFC, M1C) assessed independently; and 2) hemispheres (left and right) within regions. Preservation of the modules was evaluated between networks using the method described by Langfelder (2011), where Z summary $>10$ indicates that the module is preserved; $2<Z$ summary $<10$ show weak to moderate evidence of preservation; and $\mathrm{Z}$ summary $<2$, means no evidence of preservation. Comparative analysis using macaque samples were performed to put discoveries in some evolutionary context. For macaques, all collected brain samples were used, which encompassed similar age stages as in the human sample (Table 1). To determine hub genes in the defined modules, intramodular connectivity was calculated according to methods described in the literature (Dong and Horvath, 2007; Horvath and Dong, 2008; Oldham et al., 2008). To enable comparisons among cortical regions and between species, each co-expression network was re-assigned such that modules with significant overlap with a human module were assigned the same label. The "userListEnrichment" function in the WGCNA package was used for the cell-type marker determination analysis. The function measures the enrichment between inputted and premade collections of brain-related lists (Miller et al., 2011).

A smaller subset with the same sample size as the macaque dataset was created from the human data to enable comparisons between species unbiased by sample size. This reduced human dataset was created by a procedure of repeatedly randomly selecting 10 samples for each brain area from both hemispheres ( 5 from left and right hemispheres, respectively) to obtain 30 samples in total. This randomized simulation was repeated 100 times and gene significance (GS) and module correlations were generated. Furthermore, module preservation was also evaluated in a simulated dataset compared to the original human dataset.

\section{Examination of Candidate Genes}

To examine the expression of candidate genes related to handedness and language function, we referred to Brandler and colleagues (2013) to retrieve single nucleotide polymorphisms (SNPs) associated with relative hand skill in individuals with dyslexia. Identified SNPs with the genome-wide level of significance $10^{-4}$ were collected and mapped to genes using a 
window of $100 \mathrm{~kb}$ on both sides of each SNP. This yielded a total of 110 genes, 43 of which were present in our dataset (Supplementary Table 2). These genes were identified in the arrays and tested to determine whether they were enriched in significant p-values in the leftright contrasts of cortical areas in humans and macaques.

In parallel, a second candidate list of genes previously related to handedness, language and/or brain asymmetry was obtained based on literature (Supplementary Table 3) and further tested in our dataset.

\section{Results}

\section{Principal component analysis of gene expression across regions, hemispheres, and species}

PCA revealed that the first two principal components (explaining $35.9 \%$ and $21.4 \%$ of the variance in human and macaque samples, respectively) present no clustering based on hemispheres or cortical region in either humans or macaques (Figure 1B). This is consistent with previous findings based on the source of the human dataset which reported only minor differences among cortical areas, with the main component of variation corresponding to developmental period (Kang et al., 2011; Pletikos et al., 2013).

\section{Differentially expressed genes between hemispheres}

Interhemispheric analyses in gene expression showed that out of the 11,554 common probes evaluated in the human and macaque arrays, not one gene was found differentially expressed between hemispheres after correcting for multiple testing (FDR $<0.05)$. This observation was consistent when using the respective unfiltered probes (22,011 for human and 44,489 for macaque) and also in further contrasts performed individually for particular regions and dividing by sex.

In the human samples the top $2.5 \%$ genes ranked by expression fold-change between hemispheres were significantly enriched in STC for categories such as detection of stimulus in sensory perception (GO:0050906, $\mathrm{p}=1.04 \mathrm{e}-9$ ), transmembrane receptor activity (GO: 0099600, $\mathrm{p}=7.22 \mathrm{E}-7$ ) and signaling receptor activity (GO:0038023, $\mathrm{p}=1.06 \mathrm{e}-4$ ), among others. In VFC, only one, and only marginally significant enrichment was found for renal absorption (GO: 0070293, p=3.23e-2), and no enrichment in M1C was found. In macaques, significantly enriched categories of metabolic and catabolic processes were found only in STC (GO:0044273, p=1.66e-3), while no enrichment was found in the other regions (Supplementary Table 4).

Spearman distance analyses of interhemispheric gene expression displayed a trend for increased divergence in humans compared to macaques in the three regions studied (Figure 1C). However, only M1C and STC displayed statistically significant differences between macaque and humans after Mann-Whitney $\mathrm{U}$ test (M1C, $p=0.02$, W $=11$; VFC, $p=0.17$, $\mathrm{W}=18 ; \mathrm{STC}, p=0.05, \mathrm{~W}=14)$. 


\section{Weighted Gene Co-expression Network Analysis}

1. Comparative analysis of human versus macaque networks-WGCNA of the three human cortical regions revealed 12 modules ranging in size from 149 (module 7) to 3,139 (module 3 ) genes. Twelve genes were not correlated strongly enough to genes in any of the 12 modules, and were thus considered background (denoted by the color gray and named hereafter as module 0 ). The expression profiles of transcripts inside a given module were summarized by their first principal component (referred to as module eigengene, ME). All modules except for two were significantly correlated to age, and one module was significantly correlated to cortical area (module $5, \mathrm{p}=0.001$ ), but no module was correlated with hemisphere (Figure 2A). We found module 1 to be enriched in astrocytic genes $(\mathrm{p}=8,31 \mathrm{e}-109)$, both module $2(\mathrm{p}=4,05 \mathrm{e}-22)$ and $8(\mathrm{p}=0,0013)$ were enriched in mitochondrial genes; while module $4(\mathrm{p}=3,83 \mathrm{e}-05), 6(\mathrm{p}=45,98 \mathrm{e}-12), 10(\mathrm{p}=1,15 \mathrm{e}-17), 11$ $(\mathrm{p}=6,81 \mathrm{e}-07)$ and $12(\mathrm{p}=7,39 \mathrm{e}-10)$ were specially enriched in neuronal genes. In particular, module 4 contained genes enriched in glutamatergic synapses $(\mathrm{p}=9,81 \mathrm{e}-13)$. Module 5 was enriched in oligodendrocytes $(p=2,62 e-130)$ and white matter $(p=3,17 e-09)$. Other modules were not particularly enriched in any cell type.

In the macaque samples, nine modules were identified. Resulting modules ranged from 121 (module 1) to 2,224 genes (module 5), with 109 genes being considered background. Interestingly, one macaque module was significantly correlated to cortical area (the module $5, p=3 e-04)$, coinciding with the one that was correlated in humans and showing good preservation between both species. GO analysis of this module (module 5 in humans) revealed pathways linked to biological adhesion ( $\operatorname{adj}-\mathrm{P}=7,19 \mathrm{e}-3$ ), regulation of nervous system development (adj-P=8,73e-3), cellular development process (adj-P=7,72e-3), and regulation of neurogenesis (adj-P $=1.11 \mathrm{e}-02)$. Three modules were correlated to age (modules 3, 7 and 9); however, none was correlated with hemisphere. Overall, both human and macaque modules showed high similarity with previously described brain co-expression networks which confirm their reproducibility and validity (Cahoy et al., 2008; Miller et al., 2010; Oldham et al., 2008, 2006).

Finally, the function modulePreservation() was used to assess the overall significance of the observed preservation statistics (Langfelder et al., 2011). In all cortical areas, module 1 was always poorly preserved in macaque brains (Z-summary < 10). Interestingly, this module was strongly enriched for astrocytic markers and microglia-type 2 in all regions. Hub genes for this module were: $A G T$ (mostly present in astrocytes), $W L S$, and NOTCH2. Two other modules ( 2 and 9) also differed between species in STC and VFC. In contrast, five other modules (M3, M4, M5, M11 and M12) were always well preserved (Z-summary > 10) in the surveyed regions (Figure 2B).

2. Hemisphere-associated modules in humans-Gene co-expression modules were produced for each cortical area in the human sample and their eigengenes correlated to different factors including age and hemisphere. Across all regions, the trait that captured most of the variance was age. In human STC, however, module 3 was significantly correlated to hemisphere. This human STC module contained 2,372 genes with $C C D C 78$ as the hub gene, and had a ME correlation of $-0.46(\mathrm{p}=0.03)$ with hemisphere (Figure 2 and 
$3 \mathrm{~A})$. Among the $\mathrm{GO}$ categories most enriched in this STC module were receptor activity (GO:0004872, p-FDR=5,76e-8), molecular transducer activity (FDR=2.88e-8) and serinetype endopeptidase activity (GO: 0004252, p-FDR=1,68e-06) among others (Table 2). Furthermore, some of the genes in this STC module have been associated with brain asymmetry and language in previous research: $D R D 4$ (Atabay et al., 2014), $A R$ (Medland et al., 2005; Xiao and Jordan, 2002), CNTNAP2 (Vernes et al., 2008), COL4A2 (Eicher et al., 2013), LAMA5 (Brandler et al., 2013) and LEFTY1 (Medland 2009). Another gene in this module was $P C S K 9$, a family member of $P C S K 6$, which has been reported to be associated to hand skill (Brandler et al., 2013).

In human VFC, module 11 was correlated to hemisphere with a module significance of -0.33 $(\mathrm{P}=0.1$, Figure 3$)$. Genes in this module ( $\mathrm{n}=639)$ were not enriched in any $\mathrm{GO}$ category, although it contained mainly neuronal $(\mathrm{p}=2,71 \mathrm{e}-12)$ and nuclear genes $(\mathrm{p}=1,56 \mathrm{e}-05)$. Among the genes in the module, four were previously related to brain asymmetry and reading disabilities: DAZAP1 (Luciano et al., 2013), LMO4 (Sun et al., 2005), PLEKHA1 (Eicher et al., 2013) and NBEA (Medland, 2009).

Finally, in human M1C, we also found that module 5 was correlated to hemisphere (Module Significance $=-0.32 ; p=0.1$, Figure 3). This module, which contained 297 genes, was enriched in categories such as regulation of locomotion (GO:0040012) and cell migration (GO:0016477). Interestingly, one of these genes was PCSK6. This gene has been consistently linked to handedness in previous studies and is probably the only gene identified to play a role in handedness so far (Arning et al., 2013; Brandler et al., 2013). Also, among the genes in the module there were two genes, $R C A N 3$ and $D A B 2$, which have been previously associated with language abilities in genome-wide studies (Luciano et al., 2013; Nudel et al., 2014). Genes in modules correlated to hemisphere were evaluated to identify the number of overlapping genes (module 11 in human VFC, module 3 in STC and module 5 in M1C) and only 1 gene was present in the three modules: RSPH3.

Notably, unlike humans, no significant hemisphere-associated modules were found in any of the three cortical areas in macaque samples. To evaluate reproducibility of the results obtained, bootstrap re-sampling was performed using 100 replicates of random human subsets matching the macaque sample size ( $\mathrm{n}=30,10$ samples per region). Hemisphere correlation was analyzed in each brain area of the human bootstrap resampled dataset, yielding similar results to the complete human dataset. Briefly, modules were strongly preserved between the complete and resampled human dataset and module 3 remained correlated to hemisphere in STC, although other new modules appeared due to a fragmentation of the network topology (Figure 3A). The spread of GS over the human downsampled data distribution was also assessed and the likelihood of obtaining a human STC module 3 with the same GS than in the macaque dataset was estimated to be low (permutation, empirical p-value < 0.03) (Suppl. Figure 1).

3. Module Preservation between Hemispheres-To assess the differences in the organization of the transcriptome between left and right hemispheres in humans, separate co-expression networks were constructed for each region in each hemisphere independently. In this approach, the left hemisphere was used as the reference network and compared to the 
right. Using low sensitivity cut-off methods, all modules were found to be preserved between hemispheres ( $Z$ summary $>10)$ in all regions.

\section{Enrichment for candidate genes}

All the SNPs reported in a previous language-related genome-wide association study (Brandler et al. 2013) were collected (Supplementary Table 2). A "candidate module" composed of all the candidate genes was constructed and the correlation of the module's eigengene to hemisphere was assessed in each brain region. Similarly, a second candidate module was constructed according to previously reported genes found in the literature (Supplementary Table 3). The association of the candidate modules was not different from 1000 randomized same-size samples of genes drawn from the total dataset. In all three cortical areas, modules that we found to be particularly associated with hemisphere (module 3 in STC, module 11 in VFC and module 5 in M1C) were significantly more associated to hemisphere than the bootstrapped random modules and the "candidate modules", after Kruskal-Wallis test (STC: $\mathrm{p}=4.8 \mathrm{e}-111$; VFC: $\mathrm{p}=1.5 \mathrm{e}-107$; M1C: $\mathrm{p}=2.6 \mathrm{e}-61$ ) (Figure 3B).

The 43 candidate genes from Brandler et al. were further tested for enrichment of genes in each cortical region separately. Although not significant, approximately $30 \%$ of the 43 candidate genes were found in the human STC module 3.

\section{Discussion}

Functional brain asymmetry was initially thought to be uniquely human, reflecting speciesspecific processing demands related to language and fine motor control of the hand. However, functional and structural asymmetries have now been identified in many nonhuman primates and other species (Corballis, 2009; Frasnelli, 2013; Guadalupe et al., 2016; Ocklenburg et al., 2013a). It is still unclear whether cerebral lateralization is an effect of differential gene expression and when in development these patterns might arise. Our results indicate relatively subtle hemispheric asymmetry at the level of differential gene expression, in line with previous studies (Johnson et al., 2009, Karlebach and Francks, 2015; Pletikos et al., 2013). This observation was consistent across cortical regions in humans and macaque monkeys. It is possible that subtle changes occur at the level of the expression of individual genes that lead to differential hemispheric functioning, but which cannot be captured by the microarray approach or which are masked by statistical thresholds that are too stringent (Williams and Haines 2011). Although the PCA of total gene expression did not show any overt clustering in relation to hemisphere or cortical region in the human or macaque samples, we demonstrate here that human brains display relatively greater gene expression differences between left and right hemispheres than do macaques in all the regions studied. M1C showed the greatest global gene expression distance between hemispheres and differed significantly in interhemispheric distance between humans and macaques. This may be interpreted to be consistent with the strong hand preference observed in almost all human cultures and ethnicities (Corballis, 2003; Coren and Porac, 1977), whereas such hand dominance is not evident in macaques (Fitch and Braccini, 2013; Papademetriou et al., 2005). 
GO categories such as G-coupled receptor activity and signaling receptor activity were among the most enriched in genes with greater fold-change between hemispheres in human STC, but not other regions, nor in macaque. Thus, this finding suggests that functional differences between cerebral hemispheres in human STC may emerge from subtle changes in expression of receptors. This result is consistent with the findings of Karlebach and Francks (2015) in two-language-related areas (superior temporal sulcus and Heschl's gyrus), which showed expression laterality of GO sets involved in broad processes such as transmembrane receptor activity. It remains a possibility that non-significant results found in macaques were a consequence of the smaller sample sizes used in our approach.

Nevertheless, it is noteworthy that the current analyses of the human samples in and of themselves were able to reveal more evidence of hemispheric differences in regard to gene expression than previously described (Francks, 2015; Johnson et al., 2009, Karlebach and Francks, 2015; Pletikos et al., 2013).

\section{Limitations}

Due to limited availability of high-quality frozen tissue from both hemispheres in macaque and human brain specimens, the present study might have been somewhat underpowered to calculate module preservation statistics and associations of low-magnitude. Although results indicating greater asymmetry in expression distance measures of humans relative to macaques in our analysis might be partially related to comparisons between array platforms, it should be noted that variance in all samples was not found to be significantly different between human and macaque brain regions using a Kruskal-Wallis test. Additionally, some genes had to be excluded from the analyses since they did not reach the inclusion criteria, thus it is possible that some valuable information was lost in relation to specific genes. Finally, the overall comparative scope of this study is limited due to a lack of a third species, making it difficult to draw conclusions about which differences between humans and macaques are evolutionary specializations.

\section{Gene Co-Expression Networks}

Network-level approaches have been applied to global studies of gene expression in various biological contexts (e.g., cancer, mouse genetics, yeast genetics, and analysis of brain imaging data; Langfelder and Horvath, 2008) to discern organizational information and provide links between genetics, gene expression, and phenotype (Hilliard et al., 2012; Vanderlinden et al., 2013). The current study is focused on analyzing gene co-expression network structure to discover biological mechanisms associated with hemispheric lateralization in language- and motor-related cortical areas.

Module 5, which correlated strongly to cortical region, was also the most conserved between humans and macaques, having an overlap of $67 \%$ of genes (211/315). This module was mainly enriched in categories related to oligodendrocytes and white matter. Thus, oligodendrocytes and myelin-associated genes are key in the distinctive molecular biology of each cortical region studied (STC, VFC and M1C), supporting also a conserved role of this module in the primate brain. In contrast, module 1, which contained mostly astrocytic genes, was discovered to be the least preserved module between human and macaque brains. This observation was consistent in STC and VFC independently, and possibly reflects 
increased complexity in the form and function of astrocytes during human cortical evolution (Oberheim et al., 2006). Astrocytes are actively involved in synaptic transmission and may have played an important role in the evolution of cognitive abilities in humans (Oberheim et al., 2006; Robertson, 2014). Moreover, human astrocytes exhibit both structural and molecular specializations not shared in other primates (Oberheim et al., 2006), which strongly supports a critical role of astrocytes in human brain evolution. Of special interest is the fact that this module was strongly enriched in gene categories that modulate the rate or duration of neurodevelopment. In particular, genes controlling brain development have been shown to be targets of natural selection during human evolution and to also exert a strong influence on the size and morphology of specific functional regions of the brain, such as sensorimotor cortices and Broca's and Wernicke's areas (Gilbert et al. 2005).

Module 3 was found to be related to brain hemisphere in human STC. Despite the fact that the module itself, as well as its interconnectivity, was strongly preserved between hemispheres, the genes contained in this module were particularly over-expressed in the left hemisphere. Interestingly, gene modules constructed with candidate genes drawn from the literature were not distinguishable from a random set of genes when tested for association to hemisphere. This might be interpreted to suggest that either these candidate genes only play a role in the earlier developmental establishment of hemispheric asymmetry and do not function to maintain brain lateralization through the adulthood, or that module 3 is more lateralized than a "candidate module" constructed with genes described in previous studies of brain asymmetry. Module 3 was found to contain several genes previously suggested to be involved in brain laterality, namely dopamine receptor D4 (DRD4), AR, CNTNAP2, COL4A2, LAMA5, and LEFTY1 (Atabay et al., 2014; Brandler et al., 2013; Eicher et al., 2013; Medland et al., 2005; Schmidt et al., 2009; Vernes et al., 2008; Xiao and Jordan, 2002). $D R D 4$ is a $\mathrm{G}$ protein-coupled receptor linked to many neurological and psychiatric conditions (Schmidt et al., 2009) and has also been connected to behavioral traits in human and nonhuman primates (Bailey et al., 2007; Ebstein, 2006). Furthermore, the DRD4 gene has been shown to moderate the relationship between resting frontal brain electroencephalogram asymmetry (Schmidt et al., 2009) and associations with other disorders such as learning disabilities, antisocial behavior, and autism (Atabay et al., 2014). This module was strongly enriched in GO categories such as receptor activity and serinetype endopeptidase activity. Also, receptors were found to be particularly enriched among the genes that show larger fold-changes in expression in human STC left-right hemisphere comparisons. Previous studies have shown lateralization of multiple receptor types in functionally asymmetric brain regions, correlating with the left-sided dominance for language (Amunts et al., 2010; Fink et al., 2009). Similarly, genetic variation in other receptors such as $C C K A R$ (cholecystokinin receptor linked to dopamine release) and NMDA-receptors has been associated with language lateralization (Ocklenburg et al., 2013b, 2011). Moreover, the nigrostriatal dopaminergic system has been linked to hemispheric asymmetries in motor lateralization (de la Fuente-Fernández et al., 2000). Recently, it was shown that the KTN1 gene is associated with volumetric differences in brain structures in humans (Hibar et al. 2015). KTN1 encodes the protein kinectin, a receptor that allows vesicle binding to kinesin and is involved in vesicle transport. Interestingly, KTN1 belongs to the human STC module 3 as well. Thus, although the exact functional role of the 
receptors in hemispheric asymmetry is not clear at present, our results suggest that variation in gene expression of receptors may modulate language lateralization in human STC, probably through the glutamatergic and dopaminergic pathways.

In human VFC and M1C, although we did not find modules significantly related to hemisphere, relationships approaching conventional significance levels were observed $(\mathrm{p}=0.1)$. Notably, these modules were also more associated to hemisphere than bootstrapped random modules and modules constructed with candidate genes in the brain regions studied. In VFC, genes previously associated with language or handedness, such as DAZAP1 (Luciano et al., 2013), LMO4 (Sun et al., 2005), PLEKHA1 (Eicher et al., 2013) and NBEA (Medland, 2009) were among the genes in the module most associated with hemisphere (module 11). In M1C, module 5 was marginally related to hemisphere $(\mathrm{p}=0.1)$, including PCSK6, RCAN3 and DAB2 among its genes. PCSK6 is particularly interesting since it is the only gene that has been related to handedness with genome-wide significance (Arning et al., 2013; Brandler et al., 2013). Notably, the three cortical regions did not share the modules related to hemisphere, which implies the involvement of different genes and molecular pathways in different language- and motor-related areas.

In summary, the present study supports the conclusion that the evolution of divergence in functional asymmetry in the human cerebral cortex is due mostly to modifications of gene network interactions rather than to overt hemispheric lateralization in the expression level of individual genes. Moreover, we confirm that a gene network highly enriched in receptors is correlated with cerebral hemisphere in human STC, but not in macaque.

\section{Supplementary Material}

Refer to Web version on PubMed Central for supplementary material.

\section{Acknowledgments}

This work was supported by the National Institutes of Health (NS042867, NS073134, and NS092988), National Science Foundation (SMA-1542848) as well as the James S. McDonnell Foundation (220020293).

We would like to thank the Duke Microarray Core facility (a Duke NCI Cancer Institute and a Duke Institute for Genome Sciences and Policy shared resource facility) for their technical support, microarray data management and feedback on the generation of the microarray data reported in this manuscript. We are also grateful to David Allen Hughes for his helpful discussions and suggestions.

\section{References}

Agcaoglu O, Miller R, Mayer AR, Hugdahl K, Calhoun VD. Lateralization of resting state networks and relationship to age and gender. NeuroImage. 2015; 104:310-325. DOI: 10.1016/j.neuroimage. 2014.09.001 [PubMed: 25241084]

Amunts K, Lenzen M, Friederici AD, Schleicher A, Morosan P, Palomero-Gallagher N, Zilles K. Broca's region: novel organizational principles and multiple receptor mapping. PLoS Biol. 2010; 8:e1000489.doi: 10.1371/journal.pbio.1000489 [PubMed: 20877713]

Armour JA, Davison A, McManus IC. Genome-wide association study of handedness excludes simple genetic models. Heredity. 2014; 112:221-225. DOI: 10.1038/hdy.2013.93 [PubMed: 24065183]

Arning L, Ocklenburg S, Schulz S, Ness V, Gerding WM, Hengstler JG, Falkenstein M, Epplen JT, Güntürkün O, Beste C. PCSK6 VNTR polymorphism is associated with degree of handedness but 
not direction of handedness. PloS One. 2013; 8:e67251.doi: 10.1371/journal.pone.0067251 [PubMed: 23826248]

Atabay MM, Oz ZS, Kurtman E. The association between dopamine receptor (DRD4) gene polymorphisms and second language learning style and behavioral variability in undergraduate students in Turkey. Mol Biol Rep. 2014; 41:5215-5220. DOI: 10.1007/s11033-014-3389-x [PubMed: 24825354]

Bailey JN, Breidenthal SE, Jorgensen MJ, McCracken JT, Fairbanks LA. The association of DRD4 and novelty seeking is found in a nonhuman primate model. Psychiatr Genet. 2007; 17:23-27. DOI: 10.1097/YPG.0b013e32801140f2 [PubMed: 17167341]

Brandler WM, Morris AP, Evans DM, Scerri TS, Kemp JP, Timpson NJ, St Pourcain B, Smith GD, Ring SM, Stein J, et al. Common variants in left/right asymmetry genes and pathways are associated with relative hand skill. PLoS Genet. 2013; 9:e1003751.doi: 10.1371/journal.pgen.1003751 [PubMed: 24068947]

Broca P. Sur le siège de la faculté du langage articulé. Bull Société Anthropol Paris. 1865; 6:377-393. DOI: 10.3406/bmsap.1865.9495

Cahoy JD, Emery B, Kaushal A, Foo LC, Zamanian JL, Christopherson KS, Xing Y, Lubischer JL, Krieg PA, Krupenko SA, Thompson WJ, Barres BA. A transcriptome database for astrocytes, neurons, and oligodendrocytes: A new resource for understanding brain development and function. J Neurosci. 2008; 28:264-278. DOI: 10.1523/JNEUROSCI.4178-07.2008 [PubMed: 18171944]

Cantalupo C, Hopkins WD. Asymmetric Broca's area in great apes. Nature. 2001; 414:505.doi: 10.1038/35107134 [PubMed: 11734839]

Cashmore L, Uomini N, Chapelain A. The evolution of handedness in humans and great apes: a review and current issues. J Anthropol Sci Riv Antropol JASS Ist Ital Antropol. 2008; 86:7-35.

Corballis MC. From mouth to hand: gesture, speech, and the evolution of right-handedness. Behav Brain Sci. 2003; 26:199-208. discussion 208-260. [PubMed: 14621511]

Corballis MC. The evolution and genetics of cerebral asymmetry. Philos Trans R Soc B Biol Sci. 2009; 364:867-879. DOI: 10.1098/rstb.2008.0232

Coren S, Porac C. Fifty centuries of right-handedness: the historical record. Science. 1977; 198:631632. DOI: 10.1126/science.335510 [PubMed: 335510]

Dapretto M, Bookheimer SY. Form and content: dissociating syntax and semantics in sentence comprehension. Neuron. 1999; 24:427-432. [PubMed: 10571235]

De la Fuente A. From "differential expression" to "differential networking" - identification of dysfunctional regulatory networks in diseases. Trends Genet TIG. 2010; 26:326-333. DOI: 10.1016/j.tig.2010.05.001 [PubMed: 20570387]

De la Fuente-Fernández R, Kishore A, Calne DB, Ruth TJ, Stoessl AJ. Nigrostriatal dopamine system and motor lateralization. Behav Brain Res. 2000; 112:63-68. [PubMed: 10862936]

Dong J, Horvath S. Understanding network concepts in modules. BMC Syst Biol. 2007; 1:24.doi: 10.1186/1752-0509-1-24 [PubMed: 17547772]

Dronkers N, Ogar J. Brain areas involved in speech production. Brain. 2004; 127:1461-1462. DOI: 10.1093/brain/awh233 [PubMed: 15197111]

Ebstein RP. The molecular genetic architecture of human personality: beyond self-report questionnaires. Mol Psychiatry. 2006; 11:427-445. DOI: 10.1038/sj.mp.4001814 [PubMed: 16534505]

Eden E, Navon R, Steinfeld I, Lipson D, Yakhini Z. GOrilla: a tool for discovery and visualization of enriched GO terms in ranked gene lists. BMC Bioinformatics. 2009; 10:48.doi: 10.1186/1471-2105-10-48 [PubMed: 19192299]

Eicher JD, Powers NR, Miller LL, Akshoomoff N, Amaral DG, Bloss CS, Libiger O, Schork NJ, Darst BF, Casey BJ, et al. Genome-wide association study of shared components of reading disability and language impairment. Genes Brain Behav. 2013; 12:792-801. DOI: 10.1111/gbb.12085 [PubMed: 24024963]

Fink M, Wadsak W, Savli M, Stein P, Moser U, Hahn A, Mien L-K, Kletter K, Mitterhauser M, Kasper $\mathrm{S}$, Lanzenberger R. Lateralization of the serotonin-1A receptor distribution in language areas revealed by PET. NeuroImage. 2009; 45:598-605. DOI: 10.1016/j.neuroimage.2008.11.033 [PubMed: 19103294] 
Fitch WT, Braccini SN. Primate laterality and the biology and evolution of human handedness: a review and synthesis. Ann N Y Acad Sci. 2013; 1288:70-85. DOI: 10.1111/nyas.12071 [PubMed: 23631481]

Francks C. Exploring human brain lateralization with molecular genetics and genomics. Annals of the New York Academy of Sciences. 2015; doi: 10.1111/nyas.12770

Frasnelli E. Brain and behavioral lateralization in invertebrates. Front Psychol. 2013

Frayer DW, Lozano M, Bermúdez de Castro JM, Carbonell E, Arsuaga JL, Radovčić J, Fiore I, Bondioli L. More than 500,000 years of right-handedness in Europe. Laterality. 2012; 17:51-69. DOI: 10.1080/1357650X.2010.529451 [PubMed: 21500084]

Gannon PJ, Holloway RL, Broadfield DC, Braun AR. Asymmetry of chimpanzee planum temporale: humanlike pattern of Wernicke's brain language area homolog. Science. 1998; 279:220-222. DOI: 10.1126/science.279.5348.220 [PubMed: 9422693]

Gannon PJ, Kheck N, Hof PR. Leftward interhemispheric asymmetry of macaque monkey temporal lobe language area homolog is evident at the cytoarchitectural, but not gross anatomic level. Brain Res. 2008 Mar 14.1199:62-73. DOI: 10.1016/j.brainres.2007.12.041 [PubMed: 18262172]

Gentleman RC, Carey VJ, Bates DM, Bolstad B, Dettling M, Dudoit S, Ellis B, Gautier L, Ge Y, Gentry J, et al. Bioconductor: open software development for computational biology and bioinformatics. Genome Biol. 2004; 5(10):R80. Epub 2004 Sep 15. [PubMed: 15461798]

Gentleman, R.Carey, VJ.Huber, W.Irizarry, RA., Dudoit, S., editors. Bioinformatics and Computational Biology Solutions Using R and Bioconductor, statistics for biology and health. Springer New York; New York, NY: 2005.

Geschwind DH, Miller BL, DeCarli C, Carmelli D. Heritability of lobar brain volumes in twins supports genetic models of cerebral laterality and handedness. Proc Natl Acad Sci. 2002; 99:31763181. DOI: 10.1073/pnas.052494999 [PubMed: 11867730]

Gilbert SL, Dobyns WB, Lanh BT. Genetic links between brain development and brain evolution. Nat Rev Genet. 2005; 6(7):581-90. [PubMed: 15951746]

Gil-da-Costa R, Martin A, Lopes Ma, Muñoz M, Fritz JB, Braun AR. Species-specific calls activate homologs of Broca's and Wernicke's areas in the macaque. Nat Neurosci. 2006; 9:1064-1070. [PubMed: 16862150]

Groen MA, Whitehouse AJO, Badcock NA, Bishop DVM. Does cerebral lateralization develop? A study using functional transcranial Doppler ultrasound assessing lateralization for language production and visuospatial memory. Brain Behav. 2012; 2:256-269. DOI: 10.1002/brb3.56 [PubMed: 22741100]

Guadalupe T, Mathias SR, vanErp TGM, et al. Human subcortical brain asymmetries in 15,847 people worldwide reveal effects of age and sex. Brain Imaging Behav. 2016; doi: 10.1007/ s11682-016-9629-Z

Hibar DP, Stein JL, Renteria ME, Arias-Vasquez A, Desrivières S, Jahanshad N, Toro R, Wittfeld K, Abramovic L, Andersson M, et al. Common genetic variants influence human subcortical brain structures. Nature. 2015; 520(7546):224-9. DOI: 10.1038/nature14101 [PubMed: 25607358]

Hilliard AT, Miller JE, Horvath S, White SA. Distinct Neurogenomic States in Basal Ganglia Subregions Relate Differently to Singing Behavior in Songbirds. PLoS Comput Biol. 2012; 8:e1002773.doi: 10.1371/journal.pcbi.1002773 [PubMed: 23144607]

Hopkins WD, Leavens DA. Hand use and gestural communication in chimpanzees (Pan troglodytes). J Comp Psychol Wash DC 1983. 1998; 112:95-99.

Hopkins WD, Wesley MJ, Izard MK, Hook M, Schapiro SJ. Chimpanzees (Pan troglodytes) are predominantly right-handed: replication in three populations of apes. Behav Neurosci. 2004; 118:659-663. DOI: 10.1037/0735-7044.118.3.659 [PubMed: 15174946]

Hopkins WD, Russell JL, Cantalupo C, Freeman H, Schapiro SJ. Factors influencing the prevalence and handedness for throwing in captive chimpanzees (Pan troglodytes). J Comp Psychol Wash DC 1983. 2005; 119:363-370. DOI: 10.1037/0735-7036.119.4.363

Horvath S, Dong J. Geometric interpretation of gene coexpression network analysis. PLoS Comput Biol. 2008; 4:e1000117.doi: 10.1371/journal.pcbi.1000117 [PubMed: 18704157]

Hugdahl, K., Westerhausen, R. The two halves of the brain. The MIT Press; 2012. Ed: New. ed 
Irizarry RA, Bolstad BM, Collin F, Cope LM, Hobbs B, Speed TP. Summaries of Affymetrix genechip probe level data. Nucleic Acids Res. 2003; 31:e15. [PubMed: 12582260]

Johnson MB, Kawasawa YI, Mason CE, Krsnik Z, Coppola G, Bogdanović D, Geschwind DH, Mane SM, State MW, Sestan N. Functional and evolutionary insights into human brain development through global transcriptome analysis. Neuron. 2009; 62:494-509. DOI: 10.1016/j.neuron. 2009.03.027 [PubMed: 19477152]

Kang HJ, Kawasawa YI, Cheng F, Zhu Y, Xu X, Li M, Sousa AMM, Pletikos M, Meyer KA, Sedmak G, et al. Spatio-temporal transcriptome of the human brain. Nature. 2011; 478:483-489. DOI: 10.1038/nature10523 [PubMed: 22031440]

Karlebach G, Francks C. Lateralization of gene expression in human language cortex. Cortex. 2015; 67:30-36. [PubMed: 25863470]

Konopka G, Friedrich T, Davis-Turak J, Winden K, Oldham MC, Gao F, Chen L, Wang G-Z, Luo R, Preuss TM, Geschwind DH. Human-specific transcriptional networks in the brain. Neuron. 2012; 75:601-617. DOI: 10.1016/j.neuron.2012.05.034 [PubMed: 22920253]

Langfelder P, Horvath S. WGCNA: an R package for weighted correlation network analysis. BMC Bioinformatics. 2008; 9:559.doi: 10.1186/1471-2105-9-559 [PubMed: 19114008]

Langfelder P, Luo R, Oldham MC, Horvath S. Is my network module preserved and reproducible? PLoS Comput Biol. 2011; 7:e1001057.doi: 10.1371/journal.pcbi.1001057 [PubMed: 21283776]

Li Q, Bian S, Liu B, Hong J, Toth M, Sun T. Establishing brain functional laterality in adult mice through unilateral gene manipulation in the embryonic cortex. Cell Research. 2013; 23(9):11471149. DOI: $10.1038 / \mathrm{cr} .2013 .106$ [PubMed: 23917527]

Lozano M, Mosquera M, de Castro JMB, Arsuaga JL, Carbonell E. Right handedness of Homo heidelbergensis from Sima de los Huesos (Atapuerca, Spain) 500,000 years ago. Evol Hum Behav. 2009; 30:369-376. DOI: 10.1016/j.evolhumbehav.2009.03.001

Luciano M, Evans DM, Hansell NK, Medland SE, Montgomery GW, Martin NG, Wright MJ, Bates TC. A genome-wide association study for reading and language abilities in two population cohorts. Genes Brain Behav. 2013; 12:645-652. DOI: 10.1111/gbb.12053 [PubMed: 23738518]

McManus IC, Davison A, Armour JAL. Multilocus genetic models of handedness closely resemble single-locus models in explaining family data and are compatible with genome-wide association studies. Ann N Y Acad Sci. 2013; 1288:48-58. DOI: 10.1111/nyas.12102 [PubMed: 23631511]

Medland SE, Duffy DL, Spurdle AB, Wright MJ, Geffen GM, Montgomery GW, Martin NG. Opposite effects of androgen receptor CAG repeat length on increased risk of left-handedness in males and females. Behav Genet. 2005; 35:735-744. DOI: 10.1007/s10519-005-6187-3 [PubMed: 16273319]

Medland SE, Duffy DL, Wright MJ, Geffen GM, Hay DA, Levy F, van-Beijsterveldt CEM, Willemsen G, Townsend GC, White V, et al. Genetic influences on handedness: data from 25,732 Australian and Dutch twin families. Neuropsychologia. 2009; 47:330-337. DOI: 10.1016/j.neuropsychologia. 2008.09.005 [PubMed: 18824185]

Miller JA, Horvath S, Geschwind DH. Divergence of human and mouse brain transcriptome highlights Alzheimer disease pathways. Proc Natl Acad Sci. 2010; 107:12698-12703. DOI: 10.1073/pnas. 0914257107 [PubMed: 20616000]

Nudel R, Simpson NH, Baird G, O’Hare A, Conti-Ramsden G, Bolton PF, Hennessy ER, Ring SM, Davey Smith G, et al. SLI Consortium. Genome-wide association analyses of child genotype effects and parent-of-origin effects in specific language impairment. Genes Brain Behav. 2014; 13:418-429. DOI: 10.1111/gbb.12127 [PubMed: 24571439]

Oberheim NA, Wang X, Goldman S, Nedergaard M. Astrocytic complexity distinguishes the human brain. Trends Neurosci. 2006; 29:547-553. DOI: 10.1016/j.tins.2006.08.004 [PubMed: 16938356]

Ocklenburg S, Arning L, Hahn C, Gerding WM, Epplen JT, Güntürkün O, Beste C. Variation in the NMDA receptor 2B subunit gene GRIN2B is associated with differential language lateralization. Behav Brain Res. 2011; 225:284-289. DOI: 10.1016/j.bbr.2011.07.042 [PubMed: 21827795]

Ocklenburg S, Ströckens F, Güntürkün O. Lateralisation of conspecific vocalisation in non-human vertebrates. Laterality. 2013a; 18:1-31. [PubMed: 23231542]

Ocklenburg S, Arning L, Gerding WM, Epplen JT, Güntürkün O, Beste C. Cholecystokinin A Receptor (CCKAR) gene variation is associated with language lateralization. PLoS One. 2013b; 8:e53643.doi: 10.1371/journal.pone.0053643 [PubMed: 23341962] 
Ocklenburg S, Beste C, Arning L. Handedness genetics: considering the phenotype. Mov Sci Sport Psychol. 2014; 5:1300.doi: 10.3389/fpsyg.2014.01300

Oldham MC, Horvath S, Geschwind DH. Conservation and evolution of gene coexpression networks in human and chimpanzee brains. Proc Natl Acad Sci U S A. 2006; 103:17973-17978. DOI: 10.1073/pnas.0605938103 [PubMed: 17101986]

Oldham MC, Konopka G, Iwamoto K, Langfelder P, Kato T, Horvath S, Geschwind DH. Functional organization of the transcriptome in human brain. Nat Neurosci. 2008; 11:1271-1282. DOI: 10.1038/nn.2207 [PubMed: 18849986]

Papademetriou E, Sheu C-F, Michel GF. A meta-analysis of primate hand preferences, particularly for reaching. J Comp Psychol. 2005; 119:33-48. DOI: 10.1037/0735-7036.119.1.33 [PubMed: 15740428]

Petrides M, Tomaiuolo F, Yeterian EH, Pandya DN. The prefrontal cortex: Comparative architectonic organization in the human and the macaque monkey brains. Cortex. 2012 Jan; 48(1):46-57. Epub 2011 Jul 29. DOI: 10.1016/j.cortex.2011.07.002 [PubMed: 21872854]

Pletikos M, Sousa AMM, Sedmak G, Meyer KA, Zhu Y, Cheng F, Li M, Kawasawa YI, Sestan N. Temporal specification and bilaterality of human neocortical topographic gene expression. Neuron. 2013; doi: 10.1016/j.neuron.2013.11.018

R Development Core Team. R: a language and environment for statistical computing. $\mathrm{R}$ foundation for statistical computing; Vienna, Austria: 2014. hhtp://www.R-project.org

Robertson JM. Astrocytes and the evolution of the human brain. Med Hypotheses. 2014; 82:236-239. DOI: 10.1016/j.mehy.2013.12.004 [PubMed: 24388487]

Rudy J, Valafar F. Empirical comparison of cross-platform normalization methods for gene expression data. BMC Bioinformatics. 2011 Dec 7.12:467. [PubMed: 22151536]

Schmidt LA, Fox NA, Perez-Edgar K, Hamer DH. Linking gene, brain, and behavior: DRD4, frontal asymmetry, and temperament. Psychol Sci. 2009; 20:831-837. DOI: 10.1111/j. 1467-9280.2009.02374.x [PubMed: 19493320]

Smyth GK. Linear models and empirical bayes methods for assessing differential expression in microarray experiments. Stat Appl Genet Mol Biol. 2004; 3 Article3. doi: 10.2202/1544-6115.1027

Somers M, Ophoff RA, Aukes MF, Cantor RM, Boks MP, Dauwan M, de Visser KL, Kahn RS, Sommer IE. Linkage analysis in a Dutch population isolate shows no major gene for lefthandedness or atypical language lateralization. J Neurosci. 2015 Jun 10; 35(23):8730-6. DOI: 10.1523/JNEUROSCI.3287-14.2015 [PubMed: 26063907]

Spinozzi, G. Factors Affecting Manual Laterality in Tufted Capuchins (Cebus Apella). In: Hopkins, WD., editor. Special topics in primatology, the evolution of hemispheric specialization in primates. Elsevier; 2007. p. 204-226.

Spocter MA, Hopkins WD, Garrison AR, Bauernfeind AL, Stimpson CD, Hof PR, Sherwood CC. Wernicke's area homologue in chimpanzees (Pan troglodytes) and its relation to the appearance of modern human language. Proc R Soc Lond B Biol Sci. 2010; :rspb20100011.doi: 10.1098/rspb. 2010.0011

Sun T, Patoine C, Abu-Khalil A, Visvader J, Sum E, Cherry TJ, Orkin SH, Geschwind DH, Walsh CA. Early asymmetry of gene transcription in embryonic human left and right cerebral cortex. Science. 2005; 308:1794-1798. DOI: 10.1126/science.1110324 [PubMed: 15894532]

Sun T, Walsh CA. Molecular approaches to brain asymmetry and handedness. Nat Rev Neurosci. 2006; 7:655-662. DOI: 10.1038/nrn1930 [PubMed: 16858393]

Supek F, Bošnjak M, Škunca N, Šmuc T. REVIGO summarizes and visualizes long lists of gene ontology terms. PLoS One. 2011; 6:e21800.doi: 10.1371/journal.pone.0021800 [PubMed: 21789182]

Uomini NT. The prehistory of handedness: archaeological data and comparative ethology. J Hum Evol. 2009; 57:411-419. DOI: 10.1016/j.jhevol.2009.02.012 [PubMed: 19758680]

Vanderlinden LA, Saba LM, Kechris K, Miles MF, Hoffman PL, Tabakoff B. Whole brain and brain regional coexpression network interactions associated with predisposition to alcohol consumption. PLoS One. 2013; 8:e68878.doi: 10.1371/journal.pone.0068878 [PubMed: 23894363] 
Vauclair, J., Meguerditchian, A. Perceptual and Motor Lateralization in Two Species of Baboons. In: Hopkins, WD., editor. Special Topics in Primatology, The Evolution of Hemispheric Specialization in Primates. Elsevier; 2007. p. 182-202.

Vernes SC, Newbury DF, Abrahams BS, Winchester L, Nicod J, Groszer M, Alarcón M, Oliver PL, Davies KE, Geschwind DH, et al. A functional genetic link between distinct developmental language disorders. N Engl J Med. 2008; 359:2337-2345. DOI: 10.1056/NEJMoa0802828 [PubMed: 18987363]

Wernicke C. Der aphasische symptomencomplex: eine psychologische studie auf anatomischer basis. Cohn. 1874

Williams SM, Haines JL. Correcting away the hidden heritability. Ann Hum Genet. 2011; 75:348-350. [PubMed: 21488852]

Wilson B, Kikuchi Y, Sun L, Hunter D, Dick F, Smith K, Thiele A, Griffiths TD, Marslen-Wilson WD, Petkov CI. Auditory sequence processing reveals evolutionarily conserved regions of frontal cortex in macaques and humans. Nat Commun. 2015; 6:8901. [PubMed: 26573340]

Winden KD, Oldham MC, Mirnics K, Ebert PJ, Swan CH, Levitt P, Rubenstein JL, Horvath S, Geschwind DH. The organization of the transcriptional network in specific neuronal classes. Mol Syst Biol. 2009; 5:291.doi: 10.1038/msb.2009.46 [PubMed: 19638972]

Xiao L, Jordan CL. Sex differences, laterality, and hormonal regulation of androgen receptor immunoreactivity in rat hippocampus. Horm Behav. 2002; 42:327-336. [PubMed: 12460592]

Zhang B, Horvath S. A general framework for weighted gene co-expression network analysis. Stat Appl Genet Mol Biol. 2005; 4 Article17. doi: 10.2202/1544-6115.1128 
A

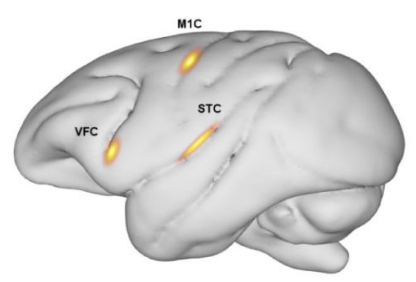

B

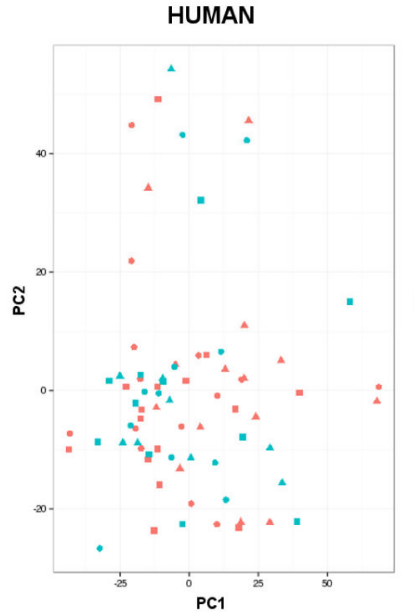

$c$

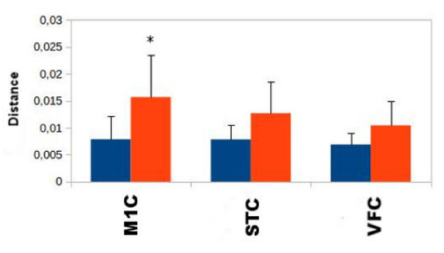

MACAQUE

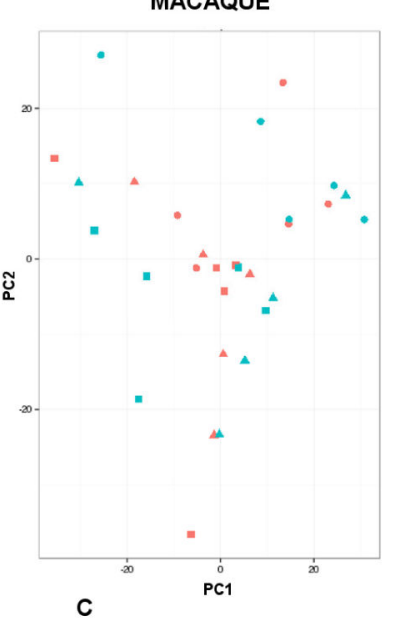

Figure 1.

A) Sample preparation in macaque specimens. Dissected areas are highlighted. Modified from Scalable Brain Atlas (https://scalablebrainatlas.incf.org). B) Principal component analysis (PCA) of human samples $(n=74)$ and macaque samples $(n=30)$ used in the present study. Samples are colored by hemisphere as shown in the upper-right legend. Notably, the PCA displays no clustering. C) Bar graphs of the measured Spearman distance coefficients between left and right hemispheres for gene pairs of human (red) and macaque (blue). 
A

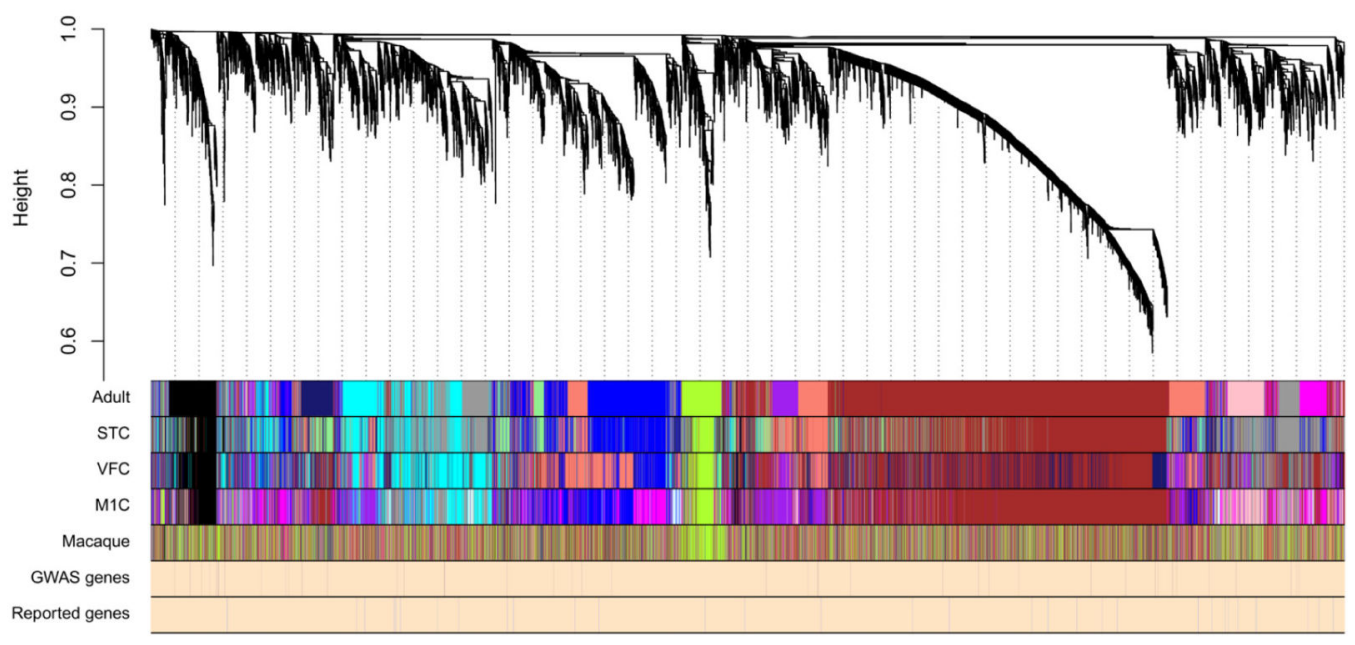

B
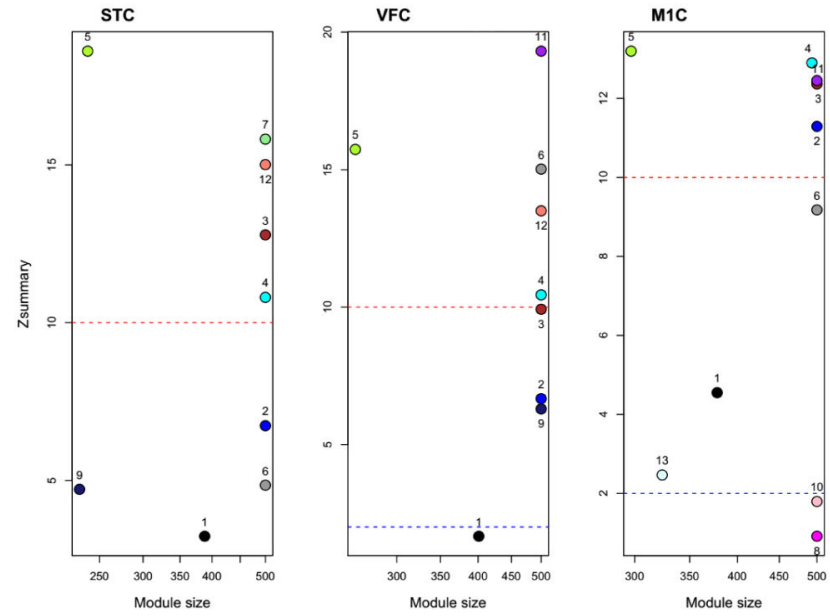

Figure 2.

A) Hierarchical clustering and visualization of gene modules in all cortical regions examined in the human dataset. The adult human network served as a reference network, module colors of other networks were redefined using mantchLabels function in WGCNA R package to match the corresponding module in the human network. Modules of coexpressed genes were assigned to colors corresponding to the branches indicated by the horizontal bars beneath the dendrogram. From top to bottom, these bars represent modules obtained using the human samples (ALL), STC samples (STC), VFC samples (VFC), M1C samples (M1C) and all macaque samples. Intercalated color bars correspond to gene significance to hemisphere (Hcor) in the respective samples. Red and blue colors correspond to correlation to the trait (being blue, more expressed in left hemisphere and red in right). Note that module 3 (in brown, correlated with hemispheric expression) is highly expressed in left hemisphere in human STC and well preserved across all brain regions. The latter bars (GWAS genes and Reported genes) indicate the location of the genes selected from Brandler et al. and from literature review, respectively. B) Preservation of modules between human modules in STC (left panel), VFC (middle panel), and M1C (right panel) and their 
homologous regions in macaque brain. A Zsummary statistic was computed for each module as an overall measure of its preservation relating to density and connectivity. 
A
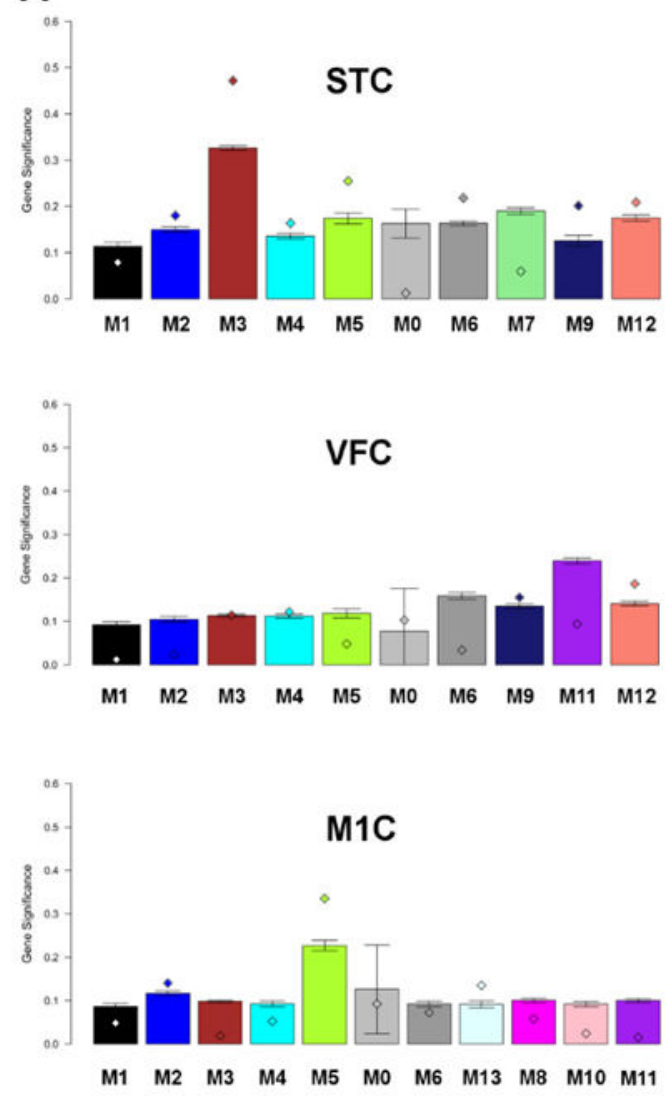

B

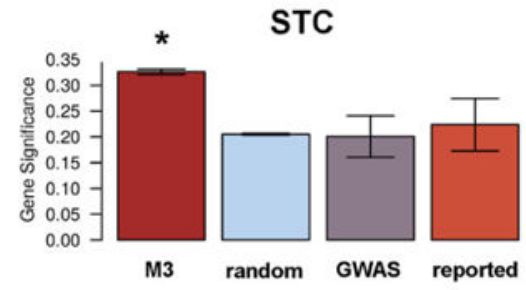

VFC

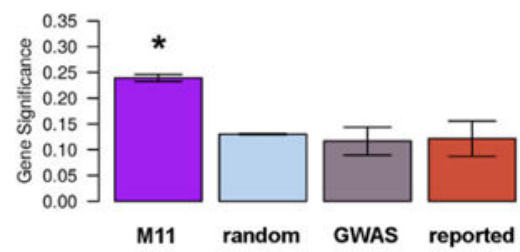

M1C

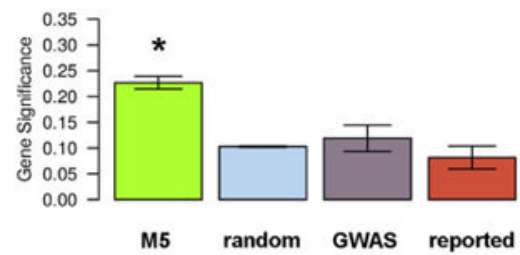

Figure 3.

A) Bar graph of mean gene significance (GS) across modules. The higher the mean gene significance in a module, the more significantly related the module is to the trait. In the figure, the GS to hemisphere is shown for human-STC (upper panel), human-VFC (middle panel) and human-M1C (lower panel) samples. Dots in the plots represent the mean GS for each module of 100 random bootstraps of the human dataset. While M-11 module in VFC was not supported with the bootstrap, M3-STC and M5-M1C where especially associated to hemisphere using 100 random bootstraps of smaller sample size. B) A "candidate module" (in gray) constructed using the 43 genes most associated to handedness in a dyslexia population and a candidate module (in tomato color) constructed with 32 genes previously related to brain asymmetry were used to calculate module significance to hemisphere (yaxes) in the studied regions in humans (STC, VFC, and M1C). In STC (upper panel) the "candidate modules" were more correlated to hemisphere $(0,2)$ than in the other brain regions. Although, they were not significantly different than the mean of a random module of the same size, permuted 500 times (in light blue). Labeled by the module number and colored, the module mostly associated to hemisphere in each region is also depicted. In all the cortical regions, the discovered module was significantly more associated to hemisphere than the "candidate modules" created with previously reported genes. Note that Kruskal- 
Wallis tests in all regions showed significant differences across the three modules represented here (STC: $\mathrm{p}=4.8 \mathrm{e}-111$; VFC: $\mathrm{p}=1.5 \mathrm{e}-107$; M1C: $\mathrm{p}=2.6 \mathrm{e}-61$ ). 


\section{Table 1}

List of macaque brains analyzed in the present study. The brains belong to five different individuals and are identified by lab ID. Sex, age, hemisphere and RIN number are also shown in the table.

\begin{tabular}{|c|c|c|c|c|c|c|}
\hline Number & Sample & Sex & Age & Area & Hemisphere & RIN $^{*}$ \\
\hline $\mathbf{1}$ & 36945 & F & 7.3 y & VFC & L & 8.1 \\
\hline $\mathbf{2}$ & 36945 & F & 7.3 y & M1C & L & 8.6 \\
\hline $\mathbf{3}$ & 36945 & F & 7.3 y & STC & L & 8.7 \\
\hline $\mathbf{4}$ & 36945 & F & 7.3 y & VFC & R & 8.6 \\
\hline $\mathbf{5}$ & 36945 & F & 7.3 y & M1C & R & 8.3 \\
\hline $\mathbf{6}$ & 36945 & F & 7.3 y & STC & R & 8.2 \\
\hline $\mathbf{7}$ & 37817 & F & 5.5 y & VFC & L & 8.4 \\
\hline $\mathbf{8}$ & 37817 & F & 5.5 y & M1C & L & 8.3 \\
\hline $\mathbf{9}$ & 37817 & F & 5.5 y & STC & L & 8.8 \\
\hline $\mathbf{1 0}$ & 37817 & F & 5.5 y & VFC & R & 8.6 \\
\hline $\mathbf{1 1}$ & 37817 & F & 5.5 y & M1C & R & 8.0 \\
\hline $\mathbf{1 2}$ & 37817 & F & 5.5 y & STC & R & 8.5 \\
\hline $\mathbf{1 3}$ & 35787 & F & 8.6 y & VFC & L & 8.8 \\
\hline $\mathbf{1 4}$ & 35787 & F & 8.6 y & M1C & L & 8.7 \\
\hline $\mathbf{1 5}$ & 35787 & F & 8.6 y & STC & L & 8.7 \\
\hline $\mathbf{1 6}$ & 35787 & F & 8.6 y & VFC & R & 8.8 \\
\hline $\mathbf{1 7}$ & 35787 & F & 8.6 y & M1C & R & 8.3 \\
\hline $\mathbf{1 8}$ & 35787 & F & 8.6 y & STC & R & 9.0 \\
\hline $\mathbf{1 9}$ & 38875 & M & 4.2 y & VFC & L & 8.0 \\
\hline $\mathbf{2 0}$ & 38875 & M & 4.2 y & M1C & L & 8.6 \\
\hline $\mathbf{2 1}$ & 38875 & M & 4.2 y & STC & L & 8.6 \\
\hline $\mathbf{2 2}$ & 38875 & M & 4.2 y & VFC & R & 8.6 \\
\hline $\mathbf{2 3}$ & 38875 & M & 4.2 y & M1C & R & 8.2 \\
\hline $\mathbf{2 4}$ & 38875 & M & 4.2 y & STC & R & 8.7 \\
\hline $\mathbf{2 5}$ & 41198 & M & 2 y & VFC & L & 8.5 \\
\hline $\mathbf{2 6}$ & 41198 & M & 2 y & M1C & L & 8.4 \\
\hline $\mathbf{2 7}$ & 41198 & M & 2 y & STC & L & 8.6 \\
\hline $\mathbf{2 8}$ & 41198 & M & 2 y & VFC & R & 8.9 \\
\hline
\end{tabular}


Table 2

Functional GO categories enriched in human STC module 3.

\begin{tabular}{|c|c|c|c|c|}
\hline GO Term & Description & P-value & FDR q-value & Enrichment \\
\hline GO:0004872 & receptor activity & $1.61 \mathrm{E}-11$ & $5.76 \mathrm{E}-8$ & 1.46 \\
\hline GO:0060089 & molecular transducer activity & $1.61 \mathrm{E}-11$ & $2.88 \mathrm{E}-8$ & 1.46 \\
\hline GO:0099600 & transmembrane receptor activity & $6.07 \mathrm{E}-10$ & 7.22E-7 & 1.49 \\
\hline GO:0038023 & signaling receptor activity & $1.16 \mathrm{E}-9$ & $1.04 \mathrm{E}-6$ & 1.46 \\
\hline GO:0004888 & transmembrane signaling receptor activity & $1.29 \mathrm{E}-9$ & $9.18 \mathrm{E}-7$ & 1.50 \\
\hline GO:0004252 & serine-type endopeptidase activity & 2.83E-9 & $1.68 \mathrm{E}-6$ & 2.37 \\
\hline GO:0008236 & serine-type peptidase activity & 7.44E-8 & $3.79 \mathrm{E}-5$ & 2.09 \\
\hline GO:0004930 & G-protein coupled receptor activity & $9.46 \mathrm{E}-8$ & $4.22 \mathrm{E}-5$ & 1.66 \\
\hline GO:0017171 & serine hydrolase activity & $1.24 \mathrm{E}-7$ & $4.9 \mathrm{E}-5$ & 2.07 \\
\hline GO:0004871 & signal transducer activity & 4.93E-7 & $1.76 \mathrm{E}-4$ & 1.31 \\
\hline GO:0005179 & hormone activity & 7.61E-6 & $2.47 \mathrm{E}-3$ & 2.23 \\
\hline GO:0005125 & cytokine activity & $1.29 \mathrm{E}-5$ & 3.83E-3 & 1.96 \\
\hline GO:0043565 & sequence-specific DNA binding & $2.25 \mathrm{E}-5$ & $6.16 \mathrm{E}-3$ & 1.30 \\
\hline GO:0004175 & endopeptidase activity & $2.68 \mathrm{E}-5$ & $6.82 \mathrm{E}-3$ & 1.52 \\
\hline GO:0005044 & scavenger receptor activity & $2.68 \mathrm{E}-5$ & $6.37 \mathrm{E}-3$ & 2.86 \\
\hline GO:0000981 & RNA polymerase II transcription factor activity, sequence-specific DNA binding & $3.18 \mathrm{E}-5$ & 7.1E-3 & 1.37 \\
\hline GO:0001071 & nucleic acid binding transcription factor activity & $5.37 \mathrm{E}-5$ & $1.13 \mathrm{E}-2$ & 1.25 \\
\hline GO:0003700 & transcription factor activity, sequence-specific DNA binding & $5.37 \mathrm{E}-5$ & $1.06 \mathrm{E}-2$ & 1.25 \\
\hline GO:0038024 & cargo receptor activity & $6.76 \mathrm{E}-5$ & $1.27 \mathrm{E}-2$ & 2.32 \\
\hline GO:0000977 & RNA polymerase II regulatory region sequence-specific DNA binding & $7.15 \mathrm{E}-5$ & $1.27 \mathrm{E}-2$ & 1.37 \\
\hline GO:0001012 & RNA polymerase II regulatory region DNA binding & $7.15 \mathrm{E}-5$ & $1.21 \mathrm{E}-2$ & 1.37 \\
\hline GO:0005201 & extracellular matrix structural constituent & $8.37 \mathrm{E}-5$ & $1.36 \mathrm{E}-2$ & 2.04 \\
\hline GO:0000975 & regulatory region DNA binding & $1.12 \mathrm{E}-4$ & $1.74 \mathrm{E}-2$ & 1.29 \\
\hline GO:0001067 & regulatory region nucleic acid binding & $1.27 \mathrm{E}-4$ & $1.88 \mathrm{E}-2$ & 1.29 \\
\hline GO:0005109 & frizzled binding & $1.48 \mathrm{E}-4$ & $2.11 \mathrm{E}-2$ & 2.49 \\
\hline GO:0005031 & tumor necrosis factor-activated receptor activity & $2.3 \mathrm{E}-4$ & $3.16 \mathrm{E}-2$ & 2.88 \\
\hline GO:0005035 & death receptor activity & $2.3 \mathrm{E}-4$ & $3.04 \mathrm{E}-2$ & 2.88 \\
\hline GO:0001228 & $\begin{array}{l}\text { transcriptional activator activity, RNA polymerase II transcription regulatory } \\
\text { region sequence-specific binding }\end{array}$ & $2.38 \mathrm{E}-4$ & 3.03E-2 & 1.47 \\
\hline GO:0008528 & G-protein coupled peptide receptor activity & $2.45 \mathrm{E}-4$ & $3.01 \mathrm{E}-2$ & 1.84 \\
\hline GO:0044212 & transcription regulatory region DNA binding & $2.59 \mathrm{E}-4$ & $3.08 \mathrm{E}-2$ & 1.27 \\
\hline GO:0000976 & transcription regulatory region sequence-specific DNA binding & $3.23 \mathrm{E}-4$ & $3.71 \mathrm{E}-2$ & 1.31 \\
\hline
\end{tabular}

Brain Struct Funct. Author manuscript; available in PMC 2018 September 01. 